\title{
Басс Н.В., Эманов С.Л. \\ К вопросу об обучении чтению и выполнению схем электрических в курсе инженерной графики в вузе
}

Брянский государственный технический университет

(Россия, Брянск)

doi: $10.18411 / \mathrm{j}-05-2021-220$

\section{Аннотация}

Рассмотрена содержательная сторона обучения студентов вузов чтению и выполнению схем электрических принципиальных. Показано значение освоения данной темы в курсе инженерной графики для успешной профессиональной деятельности будущих инженеров. Представлены практические задания, позволяющие оптимизировать учебный процесс исходя подготовленности студенческой аудитории.

Ключевые слова: схемы электрические принципиальные, чтение схем, выполнение схем, инженерная графика, графическая работа.

\section{Abstract}

The content side of teaching the students of higher education institutions to read and execute electric circuit diagrams is considered. The importance of mastering this topic in the course of engineering graphics for successful professional activity of future engineers is shown. The course materials include practical tasks which allow optimizing the training process with due regard to student's preparedness.

Keywords: electric circuit diagrams, reading of diagrams, execution of diagrams, engineering graphics, graphics work.

Профессиональная деятельность квалифицированного специалиста, связанная с радиоэлектронной техникой, системами связи и т.П., предполагает умение читать и выполнять принципиальные схемы, в частности электрические. Схемы позволяют понять принцип работы устройств. Они входят в комплект графической конструкторской документации на изделие.

В отличие от чтения несложного проекционного чертежа работа со схемами (чтение и выполнение) может быть полноценной лишь при определённом уровне технического мышления студента, понимания специфики той отрасли техники, к которой относится данная схема.

С простейшими схемами студенты встречаются до прохождения дисциплины «Инженерная графика». Понимание таких схем не требует знания условных специальных обозначений, так как на них части механизмов и приборов рисуются похожими на натуру. Здесь же им придется столкнуться с многочисленными условными обозначениями. Однако студенты должны усвоить только часть из них, остальные при необходимости будут взяты в справочнике.

Изучение темы «Схемы электрические принципиальные» следует начать с демонстрации чертежа, на котором представлены конструктивное и схематическое изображения одной и той же установки (механизма). Сопоставляя изображения, студентам легче будет выяснить особенности схемы, её простоту.

В процессе объяснения преподаватель должен довести до сведения студентов, что схемы в производственной деятельности играют немалую роль. В ряде случаев при монтаже и эксплуатации такие чертежи являются основным техническим документом, наглядно отображающим принцип действия и особенности данной установки. Изучать взаимодействие составных частей сборочных единиц и определять протекающие в них процессы по сборочным чертежам довольно сложно, а иногда и невозможно. Это основная причина, вызвавшая необходимость применять во всех отраслях промышленности упрощённые изображения сборочных единиц, в которых имеются электрические, кинематические, гидравлические, пневматические и другие связи, в виде схем. 
При составлении схем условности используются не только в части обозначений узлов и деталей, но и в части построения самого чертежа. Знание особенностей схем, умение их применять помогут студентам в дальнейшем лучше воспринимать специальные технические дисциплины.

Выяснив значение схем, указывают на их широкое применение в различных отраслях промышленности. Дается классификация схем с попутной ссылкой на ГОСТы $[1,2]$. Кратко рассматриваются виды и типы схем, общие правила их выполнения. Оговариваются особенности выбора формата листов для выполнения чертежа, типы линий и требования к их выполнению. Отдельного внимания заслуживают условные графические обозначения элементов, устройств, функциональных групп на схемах. Расположение их должно обеспечивать наилучшее представление о структуре изделия и взаимодействии его составных частей [3]. Следует остановиться на особенностях представления текстовой информации. Рассматривают требования ГОСТ $2.701-2008$ об основных правилах заполнения перечня элементов, входящих в состав изделия и изображенных на схеме [1].

По слайду, на котором подобрано изображение схемы соответствующего содержания, следует провести фронтальное чтение схемы. При чтении обучаемым следует задавать вопросы, касающиеся как расшифровки условных обозначений, так и зависимости соединённых деталей и элементов. Затем целесообразно предложить каждому студенту прочитать самостоятельно несколько схем. С этой целью необходимо иметь альбомы с изображением электрических схем.

Последовательность чтения электрических схем выглядит следующим образом:

1. Определяют тип и назначение схемы, читая основную надпись и знакомясь с техническими требованиями.

2. Выясняют, какие элементы, устройства или функциональные группы входят в электрическую схему изделия.

3. Определяют, как работает данное изделие в целом, устанавливая пути электрического тока.

4. Просмотрев всю схему, приступают к изучению отдельных элементов, входящих в функциональные группы и цепи, устанавливают их назначение в схеме и выясняют параметры по перечню элементов.

Процессы чтения и выполнения схем взаимосвязаны между собой. Невозможно выполнить чертеж схемы, не прочитав ее [4].

Многолетний опыт работы специалистов со схемами показал, что выполнять и оформлять их нужно по единым правилам. Таким как организованное расположение однотипных цепей, одинаковое изображение типовых узлов и т.д. В результате схемы более наглядны и легче распознаются, а это в свою очередь способствует оптимизации и упрощению их чтения [4].

В процессе рассмотрения темы возможно использовать в качестве иллюстраций схемы достаточно простых, но вызывающих интерес изделий - компьютерная мышка, электронные и механические игрушки, схемы машин, станков, устройств, которыми оборудованы учебные мастерские, схемы изделий - утюга, стиральной машины, фена, кухонного комбайна, холодильника и т.д.

Целесообразно изготовить со студентами наглядные стенды, на которых показать наиболее используемые элементы электрических схем в натуре и представить их условные обозначения и названия.

Для того чтобы изучение данной темы не стало носить оттенок формализма, необходимо подобрать правильные задания, требующие творческого подхода к решению. Этого можно достичь следующим образом:

- Студентам предлагается готовая схема и описание к ней. Номера позиций в описании не указаны. Следует прочитать схему, пользуясь справочником, перечертить её и составить спецификацию. 
- Выдаётся аксонометрическая схема механизма. Необходимо выполнить её в виде схемы с использованием условных обозначений и составить спецификацию.

- Студент получает полу схематический чертёж узла или механизма. Следует составить схему, заменив изображения условными обозначениями и составив спецификацию.

- Студенту выдается схема, на которой все или некоторые условные обозначения заменены кружочками. Пользуясь описанием, необходимо на месте кружочков поставить соответствующие условные обозначения, взяв их из справочника, и составить спецификацию.

Последние задания требуют от студентов умения читать схематические чертежи и составлять их.

Следует обратить внимание студентов на последовательность выполнения принципиальной схемы.

1. Детально изучают изделие, схему которого требуется вычертить (выявляют состав, назначение и количество элементов, их связи, возможный размер схемы и др.).

2. Выбирают формат листа бумаги в зависимости от размеров и сложности схемы.

3. На поле чертежа размещают изображения всех элементов схемы, вычерчивая их тонкими линиями.

4. Соединяют изображения элементов линиями электрической связи.

5. Проверяют правильность изображения схемы и обводят её линиями требуемой толщины.

6. Наносят буквенно-цифровые позиционные обозначения элементов, указывают технические данные.

7. Составляют перечень элементов и заполняют основную надпись.

Графическая работа «Схема электрическая принципиальная» должна содержать два конструкторских документа. Чертеж схемы (формат А3) и перечень элементов (формат А4). Студентам необходимо выполнить принципиальную электрическую схему по заданной структурной схеме, нанести буквенно-цифровые позиционные обозначения на элементы схемы, составить перечень элементов схемы [Эманов].

На сегодняшний день выполнение принципиальных электрических схем предполагает использование компьютерных технологий. Один из графических продуктов предлагает отечественная компания АСКОН. Компас-Электрик - мощный инструмент для проектирования документации на электрооборудование. Система состоит из двух основных модулей: база данных, редактор схем. База данных включает комплектующие изделия, условные графические обозначения. В Редакторе схем создаются, редактируются и оформляются документы проекта [сайт аскон].

По нашему мнению, такой подход при рассмотрении темы «Схемы электрические принципиальные» позволит преподавателю оптимизировать обучение студентов чтению и выполнению схем, а студентам легче усвоить и запомнить предложенный материал.

$$
* * *
$$

1. ГОСТ 2.701-2008 ЕСКД. Схемы. Виды и типы. Общие требования к выполнению.

2. $\quad$ ГОСТ 2.702-2011 ЕСКД. Правила выполнения электрических схем.

3. Эманов, С.Л. Электрические схемы, печатные платы и узлы: учеб. пособие / С.Л. Эманов. Брянск: БГТУ, 2020.-112 с. - ISBN

4. Рывлина А.А. К вопросу об общности подходов в обучении выполнению и чтению электрических схем и чертежей общего вида / А.А.Рывлина, Е.И. Корзинова // Преподаватель XXI век. - 2018. №3-1. URL: https://cyberleninka.ru/article/n/k-voprosu-ob-obschnosti-podhodov-v-obucheniivypolneniyu-i-chteniyu-elektricheskih-shem-i-chertezhey-obschego-vida (дата обращения: 24.02.2021). 